\title{
Trabalhando com a história romana na Wikipédia: uma experiência em conhecimento colaborativo na universidade ${ }^{1}$
}

Working with Roman history on Wikipedia: an experience with collaborative knowledge at the university

Juliana Bastos Marques*

\section{RESUmo}

Em razão de sua imensa popularidade, a Wikipédia é hoje uma fonte inescapável, ainda que muito do seu conteúdo em História se apresente fraco, impróprio ou mesmo errôneo. Este texto visa apresentar os resultados de uma experiência didática com a leitura crítica e edição de artigos da Wikipédia em sala de aula em uma disciplina de História Antiga na graduação.

Palavras-chave: Wikipédia; educação e internet; conhecimento colaborativo.

\section{Abstract}

Nowadays, due to its tremendous popularity, Wikipedia is an unavoidable source, even though its History content may still be weak, improper, or even erroneous. This text aims to present the results of a learning experience with critical reading and editing of Wikipedia articles on classroom, at an Ancient History undergraduate course.

Keywords: Wikipedia; education and internet; collaborative knowledge.

\section{A INFLUÊNCIA DA WIKIPÉDIA}

O maior inconveniente da escrita parece-se, caro Fedro, se bem julgo, com a pintura. As figuras pintadas têm atitudes de seres vivos mas, se alguém as interrogar, manter-se-ão silenciosas, o mesmo acontecendo com os discursos: falam das coisas como se estivessem vivas, mas, se alguém os interroga, no intuito de obter algum esclarecimento, limitam-se a repetir sempre a mesma coisa. Mais: uma vez escrito, um discurso chega a toda a parte, tanto aos que o entendem quanto aos que não podem compreendê-lo e, assim, nunca se chega a saber a quem serve e a quem não serve. Quando é menoscabado, ou justamente censurado, tem sempre

\footnotetext{
* Universidade Federal do Estado do Rio de Janeiro (UniRio), Centro de Ciências Humanas, Departamento de História. Av. Pasteur, 458, Edifício José de Anchieta, sala 216, Urca. 22290-240 Rio de Janeiro - RJ - Brasil. leiunirio@gmail.com
} 
necessidade da ajuda do seu autor, pois não é capaz de se defender nem de se proteger a si mesmo. ${ }^{2}$

No diálogo Fedro, de Platão, Sócrates fala sobre os defeitos da escrita em comparação com o discurso oral. O discurso escrito teria dois grandes problemas, um derivado do outro: o texto é fixo, imutável, frágil e necessita de seu autor para ter sentido, e isso advém do fato de preservar não a memória, como aparenta, mas sim a lembrança. Perde, então, a característica vibrante do discurso oral, a participação ativa do receptor e a capacidade de mudança da percepção cognitiva. A forma do texto escrito criticada por Sócrates é a que predominou nos 2.400 anos seguintes, mas tem sido desafiada agora pelo novo paradigma da plataforma $w i k i,{ }^{3}$ sistema em que qualquer usuário da internet pode escrever e editar um texto, em tempo real. Os wikis também subvertem outra visão do conhecimento deixada pelos gregos antigos, a divisão que Aristóteles faz na Retórica entre produtor/autor - produto/discurso escrito receptor/leitor: nessa nova forma do texto, o leitor também é autor, e interfere na produção do texto de uma forma sobre a qual o autor não tem controle. A dinâmica desorganizada e sem hierarquias da escrita na plataforma wiki é, de certa forma, a epítome da fragmentação e do pastiche típicos do pós-modernismo, que, no entanto, malgrado as críticas dos modernos nostálgicos, pode ter consequências positivas na produção do conhecimento.

A enciclopédia online Wikipédia, a mais popular e bem-sucedida experiência na plataforma wiki, foi criada em 2001 por Jimmy Wales e Larry Sanger, com a proposta de oferecer, em um site gratuito e de copyright livre, ${ }^{4}$ um número ilimitado de verbetes relacionados a todo e qualquer assunto de relevância enciclopédica que refletissem o conhecimento da humanidade. ${ }^{5}$ Para isso, utiliza a plataforma wiki como um grande repositório colaborativo de natureza voluntária.

Nos seus 11 anos de existência até agora, a Wikipédia tem sido cada vez mais popular entre os usuários da internet como um todo. Disponível em 285 idiomas e contando com um número total de mais de 20 milhões de artigos na metade de 2012, ${ }^{6}$ é avaliada como o sexto maior website do mundo em termos de número de visitantes. ${ }^{7}$ No caso da Wikipédia em português, a terceira a ser criada, ainda em 2001, o número corrente de artigos é de 751 mil, e o de visitas únicas por mês é de 287 milhões. ${ }^{8}$ Com tais números, não é surpreendente 
perceber a grande popularidade do site entre estudantes brasileiros. Já há alguns anos vem se verificando em todos os níveis de ensino uma tendência de uso disseminado e acrítico do conteúdo didático da Wikipédia pelos alunos como principal fonte de estudo, até mesmo suplantando as bibliografias e o material didático utilizados pelas disciplinas.

Duas questões principais permeiam a análise do uso da Wikipédia pelos estudantes. Em primeiro lugar, nota-se uma tendência generalizada entre docentes, de Ensino Básico ou Superior, ${ }^{9}$ de se proibir ou ao menos coibir o uso da enciclopédia como fonte de pesquisa, com base na precariedade de muitas informações apresentadas no site e por receio de plágio. Em última instância, essa proibição vem se provando inviável, dado que a facilidade com que os estudantes consultam e acessam a Wikipédia ultrapassa de longe sua iniciativa de pesquisa em fontes impressas, seja como fotocópias ou em livros das bibliotecas disponíveis. Se tal tendência parece irreversível - como reflexo da vivência da geração digital atual e das que virão ${ }^{10}$-, é portanto imperioso dominar a ferramenta e revertê-la para uma fonte de consulta a mais sólida e confiável possível, orientando os estudantes a consultá-la como ponto de partida, em consonância com os próprios objetivos do texto enciclopédico. ${ }^{11}$

Somado a isso, um problema paralelo e igualmente importante que se encontra atualmente no uso indiscriminado da Wikipédia pelos estudantes é o plágio. Algumas vezes até mesmo incentivado durante o Ensino Básico, o plágio nem sempre é percebido pelos alunos como erro ou crime. ${ }^{12}$ Mesmo quando se reconhece o caráter ilícito da cópia do texto, o aluno ainda assim apresenta pouca capacidade de retrabalhar as ideias que lê e apresentá-las com suas próprias palavras, ${ }^{13}$ de forma que o plágio, se não detectado e corrigido, consolida-se como prática corrente até mesmo em textos finais durante a pós-graduação.

Esses dois aspectos se mostram especialmente preocupantes pelo fato de que o conteúdo da Wikipédia em português, aqui em se tratando especificamente dos artigos relacionados a História, é em sua maioria bastante fraco, apresentando formulações simplistas, antiquadas, incompletas, sem referência ou simplesmente errôneas. Isso se deve à própria natureza da plataforma wiki: como a redação e a edição dos artigos é livre, qualquer pessoa pode escrever sobre qualquer assunto. ${ }^{14}$ Em tese, isso tem a princípio o caráter positivo de permitir que todo e qualquer tema seja passível de fixação na enciclopédia, 
desde que reconhecida a sua relevância, pois o caráter virtual do site permite, por definição, não haver um limite físico para seu tamanho, como nas enciclopédias em papel. Assim, assuntos relevantes para diversos grupos contemporâneos (cultura da internet, temas de minorias, preservação de culturas locais) têm o mesmo espaço de expressão que os grandes temas consolidados. No entanto, esse mesmo pressuposto da Wikipédia tem levantado um sério problema de confiabilidade dos seus verbetes, muitas vezes também alvo de vandalismos ou conflitos de interesse. ${ }^{15}$

Diferentemente do que pode parecer a princípio, a Wikipédia tem regras de funcionamento, ${ }^{16}$ que, embora sejam sucintas e claras, geram uma série de restrições à adição indiscriminada de conteúdo - o que o site chama de pilares. ${ }^{17}$ Em essência, são uma combinação do formato da escrita enciclopédica com o conceito de wiki, no sentido em que presumem que as informações deverão ser relevantes, apresentadas com base em fontes externas confiáveis, com imparcialidade e equilíbrio das diferentes opiniões sobre o tema, e não devem conter pesquisa inédita. Junto a isso, o conteúdo acrescentado deverá ser de compartilhamento livre, de acordo com a licença autoral usada no site (CC-BY-SA 3.0), as interações com outros editores e usuários devem manter um grau aceitável de civilidade e boa-fé e, por fim, resumindo o espírito de colaboração voluntária e descentralizada do projeto, a última regra convida o editor a 'ser audaz', tomando a iniciativa para modificar o conteúdo do site. Dada justamente essa característica descentralizadora e a magnitude do volume de dados continuamente acrescentados, nem sempre é possível garantir que essas regras sejam seguidas, assegurando a qualidade das informações.

Quanto a esses problemas, a resposta dos defensores da Wikipédia tem sido em torno da autorregulamentação gradual do site, ${ }^{18}$ graças à vigilância constante feita por editores experientes e administradores para corrigir erros, reverter vandalismos e eventualmente bloquear usuários que ajam repetidas vezes de má-fé. Com o tempo, as contribuições construtivas tenderiam a prevalecer sobre as prejudiciais, calibrando o texto dos verbetes em uma melhora gradual. Embora o estado atual da Wikipédia em inglês já aponte para a presença de um número razoável de artigos de boa qualidade, ${ }^{19}$ é possível que ainda sejam necessários alguns anos de autorregulamentação para que os verbetes adquiram uma correção e completude compatíveis com uma qualidade amplamente aceitável. No caso da Wikipédia em português, o fato de que o 
número de editores é bem mais baixo que o da versão anglófona torna a velocidade de desenvolvimento da enciclopédia proporcionalmente mais baixa. Vários fatores são responsáveis por essa baixa adesão de editores, fatores esses que a própria Wikimedia Foundation ainda está tentando mapear. ${ }^{20}$

Faltava à Wikipédia, portanto, uma iniciativa mais sistemática para melhorar a qualidade dos seus artigos e aumentar o número de editores. ${ }^{21}$ Com isso em vista, no início do ano letivo americano de 2010, em setembro, a Wikimedia Foundation realizou o seu primeiro projeto-piloto com universidades ao recrutar professores e alunos para editar artigos sobre políticas públicas na versão em língua inglesa. ${ }^{22} \mathrm{O}$ Public Policy Initiative teve a princípio a participação de nove professores de cinco universidades americanas, os quais utilizaram a Wikipédia como plataforma para a elaboração dos trabalhos finais de seus cursos, que seriam essencialmente melhorias nos artigos ou elaboração de novos tópicos na enciclopédia. Os professores tiveram liberdade para definir o quanto tal atividade pesaria em seus programas e quais eram seus critérios de avaliação, ao passo que a Wikimedia Foundation providenciou o treinamento de monitores técnicos para as turmas, denominados 'embaixadores', os quais atuavam tanto em sala ("Embaixadores de Campus") quanto na internet ("Embaixadores Online") para ajudar os alunos na utilização das ferramentas técnicas de edição. ${ }^{23}$ Dado que vários alunos já eram wikipedistas (como se denominam os editores regulares) experientes, os embaixadores foram recrutados dentro do corpo discente, muitas vezes entre os alunos da pós-graduação.

A ideia de se trabalhar a Wikipédia em sala de aula não é nova. Iniciativas isoladas têm sido adotadas desde os primeiros anos de funcionamento do site, ${ }^{24}$ com diferentes objetivos e graus de sucesso. Sistematizar os resultados em busca de metodologias passíveis de reprodução ainda é, no entanto, um trabalho a ser realizado. Além disso, as bases teóricas que analisam as implicações da Wikipédia enquanto produção coletiva em espaço aberto também são incipientes. Em um esforço pioneiro, Robert Cummings, em livro de 2009, ${ }^{25}$ procura entender o processo de criação de conteúdo na Wikipédia por meio do conceito de commons-based peer production, ${ }^{26}$ de Yochai Benkler. Cummings defende que a Wikipédia é a plataforma ideal no sistema em que um grupo grande de pessoas se envolve na produção de um bem material de custo ínfimo, dedicando apenas o tempo que desejam e fazendo a atividade que lhes interessa, sistema esse cuja efetividade é possível exatamente graças à 
'revisão por pares' feita pelos outro usuários do site. Como o resultado desse esforço coletivo é altamente perceptível, pois a visibilidade do trabalho é muito grande e a interação produtor-receptor é facilmente percebida, a Wikipédia seria a plataforma ideal para o trabalho em disciplinas de escrita acadêmica, curso padrão nos colleges americanos.

\section{A Disciplina “HistóRIA ROMANA NA WikipédiA" 27}

No segundo semestre de 2011, depois de estabelecer contato e uma parceria informal com a Wikimedia Foundation para um projeto pioneiro no Brasil em moldes semelhantes ao projeto americano, ministrei a disciplina optativa Tópicos Especiais em História Antiga - "A história romana na Wikipédia” para o curso presencial de História da UniRio. A disciplina era indicada para o $6^{\circ}$ período, mas os vinte alunos variavam entre o $2^{\circ}$ período e aqueles prestes a se formar - o que indica uma grande heterogeneidade da turma. O eixo inicial das atividades partiu da proposta de que os alunos estariam em última instância produzindo material didático, dada a percepção generalizada de que artigos relativos a História na Wikipédia são utilizados com frequência como meio principal (e muitas vezes único) de obtenção de informações entre os estudantes, e que em seu estado corrente necessitavam intervenção. Nesse sentido, os dois planos principais de desenvolvimento da disciplina foram, em primeiro lugar, o trabalho de crítica do conteúdo existente e, em segundo, a edição dos artigos com vistas à correção e ao desenvolvimento dos temas específicos escolhidos.

A disciplina envolveu uma composição de aulas expositivas tradicionais sobre o mundo romano e aulas em laboratório de informática sobre edição técnica na Wikipédia, combinando nas duas situações atividades de leitura crítica, pesquisa e redação. Embora eu já tivesse conhecimento básico sobre edição de artigos, a disciplina também utilizou o apoio técnico de um Embaixador de Campus e dois Embaixadores Online, todos editores experientes e conhecedores do ambiente social da Wikipédia lusófona, recrutados mediante solicitação na comunidade dos editores por meio de anúncio na própria Wikipédia (na seção Esplanada ${ }^{28}$ ) e na lista de e-mails do movimento Wikimedia Brasil. ${ }^{29}$ 
A metodologia de aula e avaliação foi em grande parte empírica, dado que a iniciativa era inédita no Brasil até então. ${ }^{30} \mathrm{~A}$ disciplina foi dividida em três fases distintas, ao fim das quais uma avaliação deveria ser entregue:

Fase 1: Enquanto a estrutura de navegação e o funcionamento da edição na Wikipédia eram explicados no laboratório de informática, os alunos eram encorajados a explorar os temas sobre Roma Antiga encontrados no site, escolhendo os artigos em que gostariam de trabalhar. Questões como o plágio, a necessidade de referências e a propriedade das informações contidas nos artigos foram analisadas, tendo como resultado um relatório individual entregue por escrito, incluindo uma proposta sobre o que deveria ser melhorado. Enquanto isso, um artigo foi elaborado em conjunto por toda a turma, com base em leituras prévias e discussão em aula. $^{31}$

Fase 2: Os artigos escolhidos pelos alunos foram agrupados em cinco temas principais, com base nos quais foram elaboradas as aulas expositivas. $\mathrm{O}$ propósito dessas aulas era trabalhar conceitos mais amplos ligados aos temas escolhidos, deixando claro que as pesquisas individuais sobre os artigos escolhidos deveriam ser feitas não como cópia dos conteúdos aprendidos em sala, mas com base nas questões historiográficas levantadas nas discussões e da própria pesquisa em fontes primárias e secundárias. Foram feitos exercícios de redação baseados na leitura e interpretação da bibliografia indicada, abrangendo as principais vertentes da discussão historiográfica sobre os temas. No caso do tema sexualidade e amor na Roma antiga, a aula foi substituída por uma palestra com uma pesquisadora especialista na questão, a profa. dra. Marina Régis Cavicchioli, da UFBA, o que enriqueceu ainda mais o debate.

Ao fim dessa fase, os alunos deveriam apresentar seus artigos para avaliação de conteúdo e de adequação técnica ao formato da Wikipédia. Caso escolhessem, os alunos poderiam apresentar seu trabalho sob a forma de traduções dos mesmos artigos em outras línguas, caso argumentassem pela adequação desses textos - afinal, traduções são permitidas na Wikipédia (no entanto, apenas dois alunos escolheram essa forma de trabalho). As edições eram feitas e monitoradas em páginas de testes dos alunos, criadas como subpáginas das páginas de usuário depois do registro no site. Foi considerada para avaliação a última edição até as $23 \mathrm{~h} 59$ do dia marcado como prazo final. Até então os 
alunos recebiam feedback meu e dos embaixadores sobre o trabalho, pelas abas de discussão ${ }^{32}$ das suas páginas de teste. Concedidas as notas, os artigos foram migrados das páginas de teste para o espaço final apenas após correção técnica e de conteúdo, para evitar que fossem revertidos a suas versões anteriores por editores externos críticos a alguma eventual regra infringida (por exemplo, texto plagiado, sem referências ou 'acadêmico' demais).

Fase 3: Nessa última fase todos os alunos opinaram e ficaram livres para editar os próprios artigos e os dos colegas, aperfeiçoando os textos e corrigindo pequenos erros de português ou referências incompletas. Nessa fase ocorreu maior interação com outros editores, pelas abas de discussão dos artigos. Como avaliação final, requereu-se um segundo relatório no qual os alunos avaliariam sua experiência, incluindo sua percepção do resultado de seu trabalho e possíveis críticas ao formato do curso e à efetividade do projeto como um todo.

\section{BALANÇO DA EXPERIÊNCIA}

O trabalho de edição resultou na redação em grupo ou individualmente de 17 artigos, novos ou já existentes, que melhoraram significativamente o estado dos seguintes temas: "Amor na Roma Antiga”, "Arquitetura da Roma Antiga", "Culto imperial", "Floralia”, "Fronteiras do Império Romano", "Grécia Romana”, "História do Estudo da Sexualidade”, "Liberto (Roma Antiga)", "Magna mater", "Muralha de Adriano”, "Religião na Roma Antiga”, "Romanização", "Sacramentum", "Saturnália”, "Sexualidade na Roma Antiga”, "Vestais" e "Vestália". Além do objetivo primário de melhorar o estado dos verbetes, as características da Wikipédia permitiram que algumas deficiências estruturais de aprendizagem fossem percebidas de maneira mais clara e trabalhadas com mais atenção:

Leitura crítica: as primeiras aulas foram dedicadas à análise do texto de alguns artigos, bem como à compreensão da parte técnica de navegação e dos recursos do site. Em uma leitura conjunta, muitas vezes frase por frase, os alunos foram questionados quanto à clareza e pertinência das informações apresentadas e onde, por que e quais fontes externas deveriam ser referenciadas. Com isso, eles aprendiam sobre a natureza do texto enciclopédico como fonte terciária e as es- 
pecificidades da Wikipédia como obra de referência: ela não pode ser utilizada como fonte de pesquisa sem antes a compreensão de que é uma obra aberta, coletiva, introdutória e não necessariamente escrita por especialistas - motivo pelo qual muitas vezes incorre em erro. Na segunda fase, foi necessário um trabalho detalhado na leitura da bibliografia selecionada, para que os alunos tivessem a máxima exatidão e clareza na exposição sucinta das diferentes ideias e do debate historiográfico referente aos temas trabalhados. Foi também nesse sentido que se fez premente uma reflexão sobre as subcategorias dos temas dos artigos, já que a estrutura do texto na Wikipédia é esquematizada em vários tópicos, e não em um texto corrido.

Pesquisa: para preparar os textos dos novos verbetes, além das aulas expositivas, os alunos foram encorajados a aprender como pesquisar, tanto na internet quanto nas vias tradicionais. A habilidade de saber como procurar uma informação, atributo próprio do bibliotecário, é essencial na internet, e os alunos aprenderam a trabalhar com ferramentas de pesquisa especializadas, como o Google Scholar ${ }^{33}$ e portais de periódicos, como o SciELO ${ }^{34}$ e o JSTOR. ${ }^{35}$ Paradoxalmente, um lugar que muitos alunos descobriram como fonte de informaçoes para suas pesquisas foi a própria biblioteca, (re)descobrindo assim o valor dos livros impressos.

Redação: este foi o elemento crucial do trabalho durante o semestre. Os alunos precisavam aprender a organizar suas próprias ideias, evitando o plágio direto ou indireto, aprendendo a citar corretamente as fontes que utilizavam, e também sintetizar e comparar as diferentes ideias de autores sobre um tema. Em razão das características da Wikipédia, a escrita também deveria ser clara, objetiva e fluida, de modo que qualquer pessoa pudesse entender conceitos muitas vezes complexos, como o de romanização. Gramática e ortografia também deveriam estar corretas, pois, como o resultado do texto é público e monitorado, qualquer erro ou imprecisão iria sobressair facilmente. Por isso, o trabalho de redação precisou de um acompanhamento minucioso, tanto por mim quanto pelos embaixadores (de campus e online). Sabe-se que esse é um ponto deficiente de muitos alunos desde o ingresso na faculdade, e a falta de tempo para trabalhar em tópicos de redação nas disciplinas regulares dos cursos faz que muitas vezes os estudantes se formem e até ingressem na pós-graduação sem conhecimento seguro de técnicas de escrita e retórica e mesmo de tópicos pontuais, como a citação de referências em ABNT.

Um ponto importante trabalhado com os alunos foi a discussão sobre autoria na Wikipédia, cujo padrão é o oposto do padrão acadêmico tradicional. 
$\mathrm{Na}$ academia supõe-se como condição sine qua non que haja um ou mais autores para determinado texto, responsáveis pelo conteúdo e que tenham uma qualificação mínima reconhecida por seus pares para que se justifique a autoridade de sua argumentação. São proprietários do texto na sua forma total, e a reapropriação, fragmentação e modificação deste sem prévia autorização constitui plágio, reconhecido legalmente como crime. O texto wiki subverte totalmente essa lógica, pois, como vimos, ao inverso do discurso escrito criticado por Sócrates, não tem autoria definida nem é fixo. ${ }^{36} \mathrm{~A}$ rigor, é possível detectar quem escreveu os artigos, porque a Wikipédia conserva o histórico de todas as edições com a identificação dos editores registrados, passíveis de identificação caso o usuário se registre com seu próprio nome ou se identifique na página de usuário a que tem direito. No entanto, a proposta do site é clara: ninguém é dono de um artigo, que eventualmente será modificado - para melhor ou para pior. Cabe ao editor interessado acompanhar as mudanças e revertê-las ou aceitá-las, e para reverter é importante poder argumentar pela mudança, dentro das regras dos cinco pilares, no resumo da edição feita ou na aba de discussão do artigo. Esse é um elemento de difícil assimilação no mundo acadêmico, mas acredito que tal dinâmica colaborativa e aberta venha a possibilitar o desenvolvimento de habilidades argumentativas que podem vir a ser revertidas para a própria escrita acadêmica.

Para um resultado bem-sucedido dentro do quadro empírico da metodologia adotada, observou-se, no entanto, a presença de alguns fatores fundamentais. Embora ainda não tenhamos elementos para afirmar que tais fatores sejam obrigatórios, em maior ou menor grau, nos modelos de trabalho a serem delineados com a Wikipédia em sala de aula, observou-se que outros cursos já ministrados no Brasil dentro do mesmo projeto não conseguiram alcançar resultados satisfatórios no mesmo grau, ${ }^{37}$ em razão de uma ou mais deficiências estratégicas relacionadas aos seguintes pontos:

- O professor deve se envolver na aprendizagem das técnicas de edição e nas dinâmicas das páginas de discussão dos alunos, ainda que minimamente. Isso inclui a verificação contínua dos trabalhos feitos no site pelos alunos e o acompanhamento das monitorias dos embaixadores. Registrar-se no site e fazer algumas edições possibilitam ao professor entender melhor os eventuais problemas dos alunos com as atividades propostas. 
- Até que esteja disponível uma capacitação testada e eficiente dos embaixadores, é necessário que o/a Embaixador/a de Campus (de preferência) ou os Embaixadores Online já sejam editores experientes e saibam lidar com eventuais problemas na relação com os wikipedistas regulares. Existe a possibilidade de que durante o andamento da disciplina os alunos se vejam envolvidos em processos de reversão de edições, promovidos por editores que julguem que as alterações feitas infringem algum dos cinco pilares, ou em discussões sobre conteúdos que podem vir a ser extensas e desgastantes. A Wikipédia lusófona é uma das mais propensas a longas discussões sobre a propriedade das informações inseridas, com eventuais disputas acirradas entre editores ${ }^{38}-$ portanto, a não ser que sejam exatamente essas dinâmicas o objetivo da disciplina, é importante não desmotivar os alunos em suas edições, evitando o máximo possível esse tipo de conflitos. Assim, para que o professor encontre voluntários capacitados e dispostos, faz-se necessária a mediação com a coordenação da Wikimedia Foundation para o programa. ${ }^{39}$

- Uma maneira bastante segura de evitar conflitos com wikipedistas durante a realização da disciplina é fazer que os alunos escrevam seus artigos apenas em suas páginas de teste, e que após a avaliação eles sejam corrigidos pelo/a professor e embaixadores, para que então possam ser 'colocados no ar'. Este modelo não é consenso entre os professores que adotaram o projeto até agora, mas se provou fácil e seguro.

- A utilização de uma lista de e-mails paralela às atividades na Wikipédia foi muito importante para solucionar as dúvidas técnicas e conceituais dos alunos durante o curso, especialmente no final da segunda fase, quando se aproximava o prazo de entrega dos artigos. Os wikipedistas costumam usar e recomendar os espaços apropriados para ajuda dentro do próprio site, como, por exemplo, o chat IRC, o Café dos Novatos $\left(\right.$ ambos com links na Esplanada ${ }^{40}$ ) e as próprias abas de discussão de todas as páginas, mas esse formato pode ser pouco familiar aos alunos.

Junto aos resultados positivos, algumas dificuldades específicas foram encontradas, em especial a paradoxal postura passiva dos alunos em diversos momentos. Acostumados ao ambiente da internet e da participação constante nas redes sociais, tiveram, no entanto, certa resistência à iniciativa das atividades propostas em aula. Talvez pelo pouco ou nenhum contato com laboratórios de 
informática no curso superior de História, muitas vezes foram altamente dispersivos. É possível que o ineditismo da proposta tenha sido um fator inibidor, como também a percepção - confirmada ao longo do semestre - de que editar na Wikipédia não é algo tão fácil quanto parece a princípio. De fato, parece necessário explicitar o alcance dos resultados do trabalho nos artigos, pois os alunos não tinham uma percepção evidente desse aspecto de início. Foi apenas depois da publicação dos artigos no site que cresceu a consciência de que os alunos estavam, de fato, produzindo material didático e elaborando conteúdo para um público extraordinariamente amplo. Como exemplo desse alcance, o artigo "Religião na Roma Antiga" tem uma média de 4 mil visitas por mês. ${ }^{41}$ Além dessas dificuldades, provou-se que a apresentação dos tópicos técnicos de edição longe do prazo final de entrega dos artigos, intercalados pelas aulas expositivas, levou os alunos a esquecerem vários procedimentos, os quais tiveram de ser relembrados pelos embaixadores na lista de e-mails. Sendo assim, é possível que a divisão entre o conteúdo tradicional da disciplina e o trabalho no site seja mais bem-sucedida se a edição em si for ensinada concomitantemente ao trabalho dos alunos.

Os relatórios finais entregues na Fase 3 da disciplina explicitam algumas percepções das atividades e do projeto como um todo. Quase todos os alunos reportaram um considerável desconhecimento no início do semestre sobre o que era a Wikipédia, sobre como ela funcionava e quem a editava e monitorava. Muitos se mostraram surpresos ao saber que eles mesmos poderiam adicionar e corrigir informações, e relataram tanto o uso regular quanto uma forte desconfiança em relação à qualidade do que liam antes no site. Uma resistência em particular também se fez presente: deixar a postura acadêmica de lado e evitar pesquisa inédita e uma complexidade maior do texto - aspecto ressaltado especialmente pelos alunos com Iniciação Científica em curso. Além disso, muitos se sentiram inseguros por terem de escolher os artigos que trabalhariam, e manifestaram preferência por artigos predefinidos. No geral, porém, os alunos compreenderam os objetivos da disciplina e a importância de um uso consciente da Wikipédia, bem como do alcance de suas contribuições.

São dois os motivos principais que justificam a importância do projeto. Em primeiro lugar, como já apresentado, o caráter quase onipresente da Wikipédia entre os estudantes brasileiros de todos os níveis torna imperioso melhorar a qualidade dos verbetes, em particular no campo da História. Tal 
iniciativa também tem como ponto positivo uma aproximação maior da produção intelectual nas universidades com a sociedade, ponto recorrente nas críticas ao distanciamento dos acadêmicos. Desta forma, a universidade responde a uma demanda social e dialoga diretamente com milhões de pessoas em todo o mundo de língua portuguesa.

Concomitantemente, o fazer em si do trabalho leva os alunos a desenvolverem e aperfeiçoarem habilidades e competências cruciais para seu desenvolvimento acadêmico. No entanto, é importante frisar novamente que nem todas as atividades relacionadas à edição na Wikipédia são análogas à produção acadêmica. Como vimos, o caráter enciclopédico do texto dos verbetes deve, a princípio, seguir os chamados 'cinco pilares' da Wikipédia: ${ }^{42}$

- a pesquisa não deve ser inédita, mas deve ser rigorosa e se basear em fontes fiáveis;

- o texto deve ser imparcial;

- o conteúdo é de licença livre (não há crédito explícito para autoria);

- devem-se seguir determinadas normas de conduta na relação entre editores, com um debate equilibrado e que assuma a boa-fé; e

- a iniciativa de editar deve ser encorajada, respeitadas as regras anteriores ('seja audaz').

Isso implica uma diferença crucial em relação ao mundo acadêmico, que se resume nas questões da autoria, da autoridade e da originalidade da pesquisa. No entanto, acredito que, devidamente contextualizadas, as diferenças acabam por se complementar na formação ampla do aluno, ao invés de se antagonizarem. Sendo assim, o uso da Wikipédia se mostra como uma forma específica de aprendizagem, que vem a complementar a formação universitária dos alunos envolvidos. É nesse mesmo sentido que Cummings afirma que a atividade com a Wikipédia seria um passo intermediário entre o ambiente de absorção de conteúdo generalista do Ensino Médio e o de produção de conhecimento especializado da academia. ${ }^{43}$

Existem várias wikis já em uso em diferentes iniciativas didáticas no ambiente universitário, desde a Plataforma Moodle ${ }^{44}$ amplamente utilizada nos cursos brasileiros de Educação a Distância, inclusive na própria UniRio, até wikis individuais de instituições, como a da Fundação Getulio Vargas. ${ }^{45}$ Suas 
possibilidades e vantagens têm sido estudadas, ${ }^{46}$ mas apresentam significativas desvantagens em relação à Wikipédia. A imensa popularidade desta torna patente para os alunos-editores a utilidade de seu trabalho, que será lido por milhares de pessoas, e a presença constante de editores e administradores que monitoram as edições e o cumprimento dos cinco pilares resulta em um acompanhamento contínuo do trabalho realizado. ${ }^{47}$

Dado que os verbetes da Wikipédia estão em constante aperfeiçoamento, os alunos aprendem que seu texto será eventualmente alterado, para melhor ou para pior, de modo que podem se tornar atentos para acompanhar o trabalho realizado após o fim do semestre (como observado com alguns alunos da turma, que continuam a editar). Também aprendem a justificar suas alterações, um hábito encorajado entre os editores da Wikipédia, argumentando seus pontos de vista com a comunidade de editores e aperfeiçoando a troca de ideias e dinâmicas de trabalho colaborativo. Embora a pesquisa acadêmica seja eminentemente autoral e individual, incentivar também o diálogo colabora para construir um ambiente de aprendizagem e pesquisa mais rico e estimulante.

\section{NOTAS}

${ }^{1}$ Agradeço a Otavio Louvem e ao prof. dr. José da Costa Filho (UniRio) a ajuda e as sugestões.

${ }^{2}$ PLATÃO. Fedro, 275 d-e. Trad. Pinharanda Gomes. Lisboa: Guimarães Ed., 2000. p.122123.

${ }^{3}$ Palavra havaiana que significa 'rápido'.

${ }^{4} \mathrm{O}$ sistema de direitos autorais da Wikipédia é a Atribuição-Compartilhamento pela mesma licença 3.0 Não Adaptada (CC BY-SA 3.0). Para mais informações: http:// creativecommons.org/licenses/by-sa/3.0/deed.pt_BR; Acesso em: 28 ago. 2012.

${ }^{5} \mathrm{O}$ slogan da Wikipédia, criado por Jimmy Wales, é "Imagine a world in which every single person on the planet is given free access to the sum of all human knowledge". Wikimedia Foundation annual report 2011-2012. Disponível em: http://wikimediafoundation.org/ wiki/Annual_Report; Acesso em: 28 ago. 2012.

${ }^{6}$ As principais estatísticas sobre a Wikipédia podem ser encontradas em http://stats. wikimedia.org/EN/Sitemap.htm; Acesso em: 28 ago. 2012.

${ }^{7}$ De acordo com as estatísticas em http://www.alexa.com/topsites, ago. 2012.

${ }^{8} \mathrm{http}: / /$ stats.wikimedia.org/wikimedia/squids/SquidReportPageViewsPerCountry Over view2011Q4.htm; Acesso em: 28 ago. 2012. 
9 SOYLU, Firat. Academics' Views On and Uses of Wikipedia. GNOVIS, v.IX, n.2, Spring 2009. Disponível em: http://gnovisjournal.org/2009/05/13/academics-views-and-useswikipedia; Acesso em: 28 ago. 2012.

${ }^{10}$ Sobre a importância do desenvolvimento de competências em informação no Brasil, ver CAVALCANTE, Lídia Eugênia. Políticas de formação para a competência informacional: o papel das universidades. Revista Brasileira de Biblioteconomia e Documentação - Nova Série, São Paulo, v.2, n.2, p.47-62, dez. 2006, disponível em: http://rbbd.febab.org.br/rbbd/ article/view/17/5; e DUDZIAK, Elizabeth Adriana. Os faróis da sociedade de informação: uma análise crítica sobre a situação da competência em informação no Brasil. Informação e Sociedade: Estudos, João Pessoa, v.18, n.2, p. 41-53, maio-ago. 2008, disponível em: www. producao.sibi.usp.br/handle/2012.1/16882; Acessos em: 28 ago. 2012.

${ }^{11}$ VIEIRA, Marli Fátima Vick. A Wikipédia é confiável? Credibilidade, utilização de uma enciclopédia online no ambiente escolar. Dissertação (Mestrado em Educação) - Univale. Santa Catarina, 2008. Disponível em: http://siaibib01.univali.br/pdf/Marli\%20Fatima\%20 Vick\%20Vieira.pdf; Acesso em: 28 ago. 2012.

${ }^{12}$ BARBASTEFANO, Rafael Garcia; SOUZA, Cristina Gomes de. Plágio em trabalhos acadêmicos: uma pesquisa com alunos de graduação. In: ENCONTRO NACIONAL DE ENGENHARIA DE PRODUÇÃO, 27. Anais... Foz do Iguaçu (PR): Abepro, 2007. Disponível em: www.abepro.org.br/biblioteca/ENEGEP2007_TR660482_9513.pdf; Acesso em: 28 ago. 2012.

${ }^{13}$ SILVA, Aletéia Karina Lopes da; DOMINGUES, Maria José Carvalho de Souza. Plágio no meio acadêmico: de que forma alunos de pós-graduação compreendem o tema. Perspectivas Contemporâneas, Campo Mourão (PR), v.3, n.2, p.117-135, ago.-dez. 2008. Disponível em: www.revista.grupointegrado.br/revista/index.php/perspectivascontemporaneas/ article/viewFile/448/247; Acesso em: 28 ago. 2012.

${ }^{14}$ ROSADO, Autoria textual coletiva fora do âmbito acadêmico: delineando o perfil dos wikipedistas. In: COLÓQUIO DE PESQUISAS EM EDUCAÇÃO E MÍDIA: diálogo entre culturas, 1. Rio de Janeiro: PUC-Rio/UniRio, 2007. Disponível em: http://alexandrerosado. net/attachments/005_Coloquio1AlexandreRosado.pdf; Acesso em: 28 ago. 2012.

${ }^{15}$ Disponível em: http://pt.wikipedia.org/wiki/Críticas_à_Wikipédia; Acesso em: 28 ago. 2012.

${ }^{16}$ SANTOS, J. D.; PANDINI, M. J. Wikipédia: descrição dos métodos de organização e recuperação da Enciclopédia Colaborativa. In: CONGRESSO BRASILEIRO DE BIBLIOTECONOMIA, DOCUMENTAÇÃO E CIÊNCIA DA INFORMAÇÃO, CBBD, 23. Bonito (MS), 2009.

${ }^{17}$ Disponível em: http://pt.wikipedia.org/wiki/Wikipédia:Cinco_pilares; Acesso em: 28 ago. 2012.

${ }^{18} \mathrm{O}$ cofundador do site, Larry Sanger, afastou-se do projeto por discordar desses argumentos e fundou outra enciclopédia livre em 2007, o Citizendium (http://en.citizendium.org/), atualmente disponível apenas em inglês. A princípio, as edições estariam restritas apenas a 
especialistas, mas isso tem resultado em um número muito baixo de verbetes - em 28 de agosto de 2012, não passavam de 16.272.

${ }^{19}$ Como no estudo comparativo entre artigos sobre ciência na Wikipédia e na Encyclopaedia Britannica: GILES, Jim. Internet encyclopaedias go head to head. Nature, v.438, n.7070, p.900-901, Dec. 15, 2005. Um estudo de 2012 patrocinado pela Wikimedia Foundation corrobora os dados: CASEBOURNE et al. Assessing the accuracy and quality of Wikipedia entries compared to popular online encyclopedias: a comparative preliminary study across disciplines in English, Spanish and Arabic. Epic, Brighton, UK. Disponível em: http:// upload.wikimedia.org/wikipedia/commons/2/29/EPIC_Oxford_report.pdf; Acesso em: 28 ago. 2012.

20 http://pt.wikipedia.org/wiki/Wikipédia:Central_de_pesquisas/Tendências_e_ comportamento_de_editores; Acesso em: 28 ago. 2012.

${ }^{21}$ A proporção entre usuários e editores nas Wikipédias em diferentes línguas pode ser acompanhada com atualizações mensais em http://stats.wikimedia.org/EN/ TablesCurrentStatusVerbose.htm; Acesso em: 28 ago. 2012. Note-se que, entre as dez maiores Wikipédias, a versão em português está atrás apenas da chinesa em menor proporção de editores para usuários (coluna Participation).

${ }^{22} \mathrm{O}$ artigo de Steve Kolowich no Inside Higher Ed do mesmo mês, "Wikipedia for Credit", foi o que me trouxe a atenção para o projeto: www.insidehighered.com/news/2010/09/07/ wikipedia. Cf. OBAR, Jonathan A.; ROTH, Amy. The Wikipedia public policy initiative: exploring the potential benefits of using Wikipedia in the University classroom as a tool for innovative e-pedagogy (Working paper, Aug. 29, 2011). Disponível em: http://ssrn. com/abstract=1923888; Acessos em: 28 ago. 2012.

${ }^{23}$ http://outreach.wikimedia.org/wiki/Wikipedia_Ambassador_Program e http://pt. wikipedia.org/wiki/Wikipédia:Embaixadores.

${ }^{24}$ Ver análise e bibliografia citada em WANNEMACHER, Klaus. Experiences and perspectives of Wikipedia use in higher education. International Journal of Management in Education, v.5, n.1, p.79-92, 2011. Disponível em: http://inderscience.metapress.com/ content/31g167957k810464/; Acesso em: 28 ago. 2012.

${ }^{25}$ CUMMINGS, Robert E. Lazy virtues: teaching writing in the Age of Wikipedia. Nashville: Vanderbilt University Press, 2009.

${ }^{26}$ Termo ainda sem tradução corrente para o português; cf. SIMON, Imre. Commons-based peer production, disponível em: www.ime.usp.br/ is/Benkler/cbpp.html; Acesso em: 28 ago. 2012. Simon define o termo como "uma comunidade aberta e vagamente delimitada [que] coopera, de forma essencialmente espontânea, descoordenada e voluntária para a produção de um bem informacional ou cultural que é compartilhado pela comunidade de forma neutra e transparente. Em particular, o novo método produtivo não se baseia nos mecanismos tradicionais de organização social do trabalho através de hierarquias, sinais de preços via mercados e relações de contrato e de propriedade".

${ }^{27}$ A página da disciplina na Wikipédia está disponível em: http://pt.wikipedia.org/wiki/ 
Wikipédia:Embaixadores/Disciplinas/Segundo_semestre_de_2011/A_História_Romana_ na_Wikipédia_(Juliana_Bastos_Marques); Acesso em: 28 ago. 2012.

${ }^{28} \mathrm{http} / / /$ pt.wikipedia.org/wiki/Wikipédia:Esplanada.

${ }^{29} \mathrm{https} / /$ lists.wikimedia.org/mailman/listinfo/wikimediabr-1.

${ }^{30}$ Metodologias de trabalho adotadas pelos professores americanos serviram como referência, mas não foram adotadas integralmente em razão das diferenças entre as realidades educacionais e entre as Wikipédias. Algumas das disciplinas foram publicadas como estudos de caso em uma brochura elaborada pela Wikimedia Foundation em julho de 2012: http://pt.wikipedia.org/w/index.php?title=Ficheiro:Como_os_professores_estão_ ensinando_com_a_Wikipédia.pdf\&page=1.

${ }^{31}$ http://pt.wikipedia.org/wiki/Romanização; Acesso em: 28 out. 2012 (a última edição feita pela turma é de 5 dez. 2011).

${ }^{32}$ Sobre esse recurso, ver: http://pt.wikipedia.org/wiki/Ajuda:Página_de_discussão.

${ }^{33} \mathrm{http}: / /$ scholar.google.com.

${ }^{34} \mathrm{http}: / /$ www.scielo.org.

${ }^{35} \mathrm{http}: / /$ www.jstor.org.

${ }^{36}$ JESUS, Ana Maria Ribas de. Wiki: ferramenta de autoria e colaboração na Web 2.0. In: ENCONTRO NACIONAL DE HIPERTEXTO E TECNOLOGIAS EDUCACIONAIS., 4. Anais... Uniso, 2011. Disponível em: http://www.uniso.br/ead/hipertexto/anais/07_ AnaRibas1.pdf; Acesso em: 28 ago. 2012.

${ }^{37}$ http://pt.wikipedia.org/wiki/Wikipédia:Wikipédia_na_Universidade/Cursos. As abas de discussão dessa página, da página dos embaixadores e das páginas de cada curso trazem questões sobre as dificuldades encontradas e os resultados conseguidos nas disciplinas.

${ }^{38}$ As razões para isso ainda estão sendo estudadas. Cf. CAMPOS, Aline de. Conflitos na colaboração: um estudo das tensões em processos de escrita coletiva na web 2.0. Dissertação (Mestrado) - Universidade Federal do Rio Grande do Sul. Porto Alegre, 2009. Disponível em: http://hdl.handle.net/10183/16928; SERRANO, Paulo H. Participações em uma comunidade de prática; O sustentáculo da Wikipédia. In: ENCONTRO NACIONAL SOBRE HIPERTEXTO, 3. Anais... Belo Horizonte: Anais Hipertexto, 2009. Disponível em: www.ufpe.br/nehte/hipertexto2009/anais/p-w/participacoes-em-uma-comunidade.pdf; e SERRANO, Paulo Henrique. Coerência entre princípios e práticas na Wikipédia lusófona: uma análise semiótica. Dissertação (Mestrado) - Universidade Federal de Minas Gerais. Belo Horizonte, 2011. Disponível em: http://dspace.lcc.ufmg.br/dspace/handle/1843/ DAJR-8M6R2F; Acessos em: 28 ago. 2012.

${ }^{39} \mathrm{http} / / /$ pt.wikipedia.org/wiki/Wikipédia:Wikipédia_na_Universidade/Ajuda.

${ }^{40} \mathrm{http}: / /$ pt.wikipedia.org/wiki/Wikipédia:Esplanada.

${ }^{41}$ As estatísticas de visitação dos artigos podem ser visualizadas na aba "Ver histórico", "Ferramentas: (...) número de visitas". 
${ }^{42}$ Cf. nota 16.

43 "CBPP [commons-based peer production] writing assignments assist them in understanding the role of producing knowledge for our culture rather than only consuming it". CUMMINGS, 2009, p.6.

${ }^{44}$ ROSADO, Luiz Alexandre da Silva; BOHADANA, Estrella. Autoria coletiva na Educação: análise da ferramenta wiki para cooperação e colaboração no ambiente virtual de aprendizagem Moodle. In: ENCONTRO DE EDUCAÇÃO E TECNOLOGIAS DE INFORMAÇÃO E COMUNICAÇÃO, 5. Anais... Rio de Janeiro: Universidade Estácio de Sá, 2007. Disponível em: http://etic2008.files.wordpress.com/2008/11/unesaluizalexandre.pdf; Acesso em: 28 ago. 2012.

${ }^{45}$ http://epge.fgv.br/we.

${ }^{46}$ GOMES, Maria Rodrigues. A ferramenta wiki: uma experiência pedagógica. Comunicação \& Educação, v.XVII, n.2, maio-ago. 2007. Disponível em: www.revistasusp.sibi.usp.br/ pdf/ced/v12n2/v12n2a12.pdf; BOTTENTUIT Jr., João Batista; COUTINHO, Clara Pereira. Wikis em educação: potencialidades e contextos de utilização. In: ENCONTRO SOBRE WEB 2.0, Braga, 2008. Actas... Disponível em: http://hdl.handle.net/1822/8460; Acessos em: 28 ago. 2012.

${ }^{47}$ SAORÍN PÉREZ, Tomás; DE HARO Y DE SAN MATEO, María Verónica; PASTOR SÁNCHEZ, Juan Antonio. Posibilidades de Wikipedia en la docencia universitaria: elaboración colaborativa de conocimiento. Ibersid - Revista de sistemas de información y documentación, v.5, p.89-97, 2011. Disponível em: http://ibersid.eu/ojs/index.php/ibersid/ article/view/3915; Acesso em: 22 ago. 2012.

Texto recebido em $1^{\circ}$ de setembro de 2012. Aprovado em 20 de novembro de 2012. 